Article

\title{
Exploring the Influence of an Urban Water System on Housing Prices: Case Study of Zhengzhou
}

\author{
Junjie $\mathrm{Li}^{1, *(1)}$, Yaduo $\mathrm{Hu}^{2}{ }^{2}$ and Chunlu Liu ${ }^{3}$ (1) \\ 1 School of Management Engineering, Zhengzhou University, Zhengzhou 450001, China \\ 2 College of Management and Economics, Tianjin University, Tianjin 300072, China; hyduo@tju.edu.cn \\ 3 School of Architecture and Built Environment, Deakin University, Victoria 3220, Australia; \\ Chunlu.Liu@deakin.edu.au \\ * Correspondence: lijunjie@zzu.edu.cn; Tel.: +86-1883-716-3612
}

Received: 2 January 2020; Accepted: 1 February 2020; Published: 3 March 2020

\begin{abstract}
A good living environment is the foundation of sustainable housing. Exploring the external influence of environmental factors on housing prices is one of the key issues in the field of real estate research; however, the current study of the urban water landscape on the spillover effect of housing prices is not sufficient. Taking the Zhengzhou residential market as an example, this paper analyzes the effect of an urban water system on residential prices by constructing the traditional Hedonic price model, spatial lag model (SLM) and geographically weighted regression model (GWR) by selecting the main water system and 678 points of residential data in the main urban area. The results show that the accessibility of rivers and lakes and the width and water quality of rivers have a significant effect on residential prices, and the impact of lakes is greater than that of rivers. The spatial heterogeneity of the water system effect is further revealed by adopting spatial lag model and geographically weighted regression model, and the effect of the water system is gradually reduced from the eastern urban area to the western urban area. The results of this study are of great practical significance to the government's municipal planning, water environment management and housing market management.
\end{abstract}

Keywords: water system; housing prices; Hedonic price model; spatial lag model; geo-weighted regression model

\section{Introduction}

With the improvement of living standards, the improvement of urban life quality is no longer part dependent on the development of urbanization and industrialization, but is inextricably linked to a good natural environment [1]. People are also beginning to lean towards an environmentally friendly lifestyle, hoping to be able to have sound environmental facilities near their place of residence. Some studies have shown high correlations between housing preferences, environmental facilities and residential attractiveness [2,3]. The presence of and proximity to water influences human settlement decisions, because water has been able to characterize the environment and affect human health since prehistoric times [4]. Water system in cities, as important environmental resources, are of great comfort in people's lives because they reduce the amount of wind and sand, bring moisture and clean air, provide residents with low density and an open space of view, and living near a water system can relieve stress and relax people [5].

Taking the major urban water system resources as the research object, some research confirmed that lakes [6,7], rivers [8,9], and wetlands and oceans [10-12] all have a positive impact on housing prices from the perspective of landscape accessibility, which suggests that the closer a home is to the water system, the higher premium price it has. Other scholars analyzed the relationship between water 
system visibility and housing price. Luttik [13], for example, found that the price of a housing which can overlook the water would increase by $8 \%$ to $10 \%$. Although the influence of the relative position of housing and water system is important, the influence of the characteristics of the water system itself on the housing price cannot be ignored. Previously published studies have found that the change of water level [14] and quality [15,16] of the adjacent water system can also have an impact on housing prices.

Some scholars have found that the impact of environmental facilities on housing prices is not simply a linear relationship, which can be attributed to the negative externalities of the water system, such as noise and flood. For example, it has been noted that the noise of the shipping will have a negative impact on the price of housing within a certain distance of the Grand Canal in Hangzhou [17]. With the increasing impact of climate change on urban streams, the relationship between the flood risk exposure associated with proximity to water and property price has been of significant interest to scholars. Studies of water systems in the UK [18], Netherlands [19], Germany [20] and South Korea [21] have found that river flooding had negative effects on housing prices. While Atreya and Czajkowski found that housing market properties located in areas with the highest risk of flood for up to nearly a quarter mile from the nearest coastline actually command a price premium [22].

Most existing studies focus on a single river system; however, few studies have selected multiple water systems or multiple perspectives for comparative study, so it is sometimes difficult to obtain a more reliable and universal conclusion. It is a common research method to use a spatial econometric model to explore the heterogeneity of influence from local perspective. There have been a number of studies involving individual heterogeneity [23], distance heterogeneity [17], regional heterogeneity [24], and direction heterogeneity [7] that have reported the heterogeneity effects of water systems on housing prices. While the main research method adopted by most studies is just to divide the regions artificially and analyze the heterogeneity by taking them as dummy variables. With the maturity of the spatial econometrics theory and the continuous progress of geographic information technology, geographically weighted regression (GWR), a model of studying spatial heterogeneity based on nonparameter modeling ideas, is becoming more and more popular and effective method to explore spatial heterogeneity through local regression. The method has been adopted to explore the heterogeneity of the impact of environmental facilities [25], dams [26], and education facilities [27] on housing prices. The GWR model is more concise and more scientific and objective than using dud variables, and the division method is more scientific and objective. Besides, it is more intuitive is easier to understand through GIS software composition. So far, however, there has been little investigation about the heterogeneity impact of the water system through GWR method.

To fill these gaps, the spatial econometric model, which improves the traditional Hedonic price model, is adopted in this paper to control the spatial autocorrelation of housing prices and explore the spatial heterogeneity of the influence of the water system on housing prices. In addition, in order to compare the influence factors of different water systems on housing prices, multiple water systems are selected for analysis.

The main contribution of this paper is not only to explore the impact of a water system on housing prices from a global perspective, but also to draw the conclusion that the effect has heterogeneousness through comparative analysis. Firstly, the effect of lakes on housing prices is higher than that of rivers. Secondly, the effect of a water system on housing prices in different regions is different, mainly by the nature of the community itself and the regional water system distribution. Finally, the effects of different water systems depend on the characteristics of the water system and the surrounding area. These conclusions are of great functional significance to urban planning and construction and the improvement of water system environment.

The rest of this paper is organized as following. Next section introduces research areas and subjects. Section 3 provides the empirical framework, including the data, variables and models used. Then, the empirical results and discussion are presented in Section 4. Section 5 describes the conclusions and recommendations of the paper. 


\section{Research Area}

Zhengzhou City, the capital of the province of Henan, in the middle of China, is selected to be the object of analysis in this paper. Zhengzhou, which is located in the south of the North China Plain and the lower reaches of the Yellow River, is famous for its developed railway system and is also the core city of the Central Plains city group, and the national center city supported by the Chinese government. There is a total area of 7446.2 square kilometers and a population of about 10 million, under the jurisdiction of six districts and six counties. The main urban area includes Erqi, Zhongyuan, Jinshui, Huiji, Shangjie, Guancheng Hui district and the Airport Economic Comprehensive Test Zone, with an area of 549.33 square kilometers. Considering the farther distance to the main city and smaller built-up area of the Shangjie and the airport district, this paper takes other five main urban areas (Erqi, Zhongyuan, Jinshui, Huiji, Guancheng Hui district) as the research objects, with a total area of 473.58 square kilometers.

Compared with the southern cities with abundant rivers, Zhengzhou is a city where water resources are scarce with per capita water resources accounting for about one-tenth of the average Chinese person, which shows that the water system landscape is relatively scarce in this city, and then urban residents living near the water system may pay a certain premium for this scarce resource. So, it is reasonable and meaningful to take this city as a case in this paper.

The surface moisture of Zhengzhou City belongs to the Yellow River and the Huaihe River, while the main urban area is mainly located in the Huai River basin. The main rivers of the urban area are Weihe, Jialuhe, Dongfengqu, Jinshuihe, Xiongerhe, and Qilihe, and the larger lakes are Xiliuhu, Ruyihu and Longhu. These six rivers and three lakes are all selected as research objects to explore the impact of the water system on housing prices in this paper. The location of the study area and the water system is shown in Figure 1.

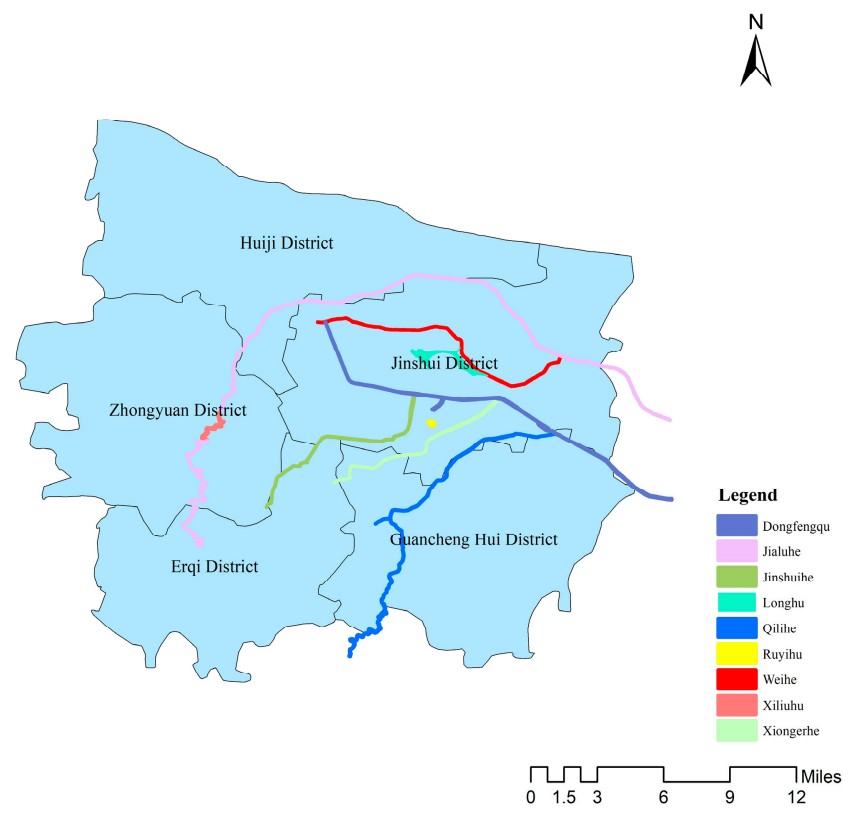

Figure 1. Distribution of main urban areas and water systems in Zhengzhou. 


\section{Data and Method}

\subsection{Variable Setting}

The average price of second-hand housing market area is regarded as a factor variable in this paper. Based on the traditional Hedonic price model and the research object, the explanatory variable setting is divided into four characteristic factors, namely structural factors, location factors, neighborhood factors and water system factors.

Structural factors mainly reflect the characteristics of the building and the community environment, through the preliminary regression analysis, taking into account the colinearity problem and the elimination of nonsignificant variables, seven explanatory variables are selected as following: building age, property category (villa is 0 , other is 1 ), plot ratio, property fee, total number of houses, total number of buildings and greening rate.

Location factors mainly consider the convenience of the community to commercial center and other destinations, including the community to the CBD distance, to the nearest top three hospital, and to the nearest business circle distance. The selection criterion of business circle is Zhengzhou's top ten business circles (Erqi Wanda, Zhongyuan Wanda, Huiji Wanda, Erqi Square, Manhattan Square, Huayunlu, Zijingshan, Jinyicheng, Langyue Park Mall, Dennis Seven Worlds).

Neighborhood factors measure transportation, living facilities, educational facilities, and environmental facilities around the neighborhood. Seven neighborhood factors are selected as explain variables, the number of primary schools within $1 \mathrm{~km}$, the number of secondary schools within $1 \mathrm{~km}$, whether there is any key primary school within $1 \mathrm{~km}$, whether there were any parks within $1 \mathrm{~km}$, the number of bus stations within $1 \mathrm{~km}$, the number of convenience stores within $500 \mathrm{~m}$, and the number of convenience stores within $500 \mathrm{~m}$. The measurement standard of $1 \mathrm{~km}$ is appropriate mainly because the walking time of $1 \mathrm{~km}$ is about $20 \mathrm{~min}$, which is an acceptable distance to most people. Bus stops and convenience stores as basic transportation and living facilities, the choice standard of $500 \mathrm{~m}$ is more appropriate.

In view of the influence of water system factors on housing price, six explanatory variables are selected to explore the effects of water system from the aspects of accessibility, water system physical characteristics and water quality. The water system as relaxing place, accessibility is one of the explanatory variables. Further, in order to explore the heterogeneity of the impact of rivers and lakes on housing prices, the distance to the river or lake is analyzed as a separate explanatory variable. At the same time, the physical properties of the water system and the water quality are also important. Larger water areas may affect the climate of smaller regions and then the influence scope is wider. A water system with better water quality will be more ornamental and popular with people. Therefore, the river surface width, lake surface area and river water quality are taken as explanatory variables. Table 1 is the summary of explanatory variable selected. 
Table 1. Variable definition and qualification.

\begin{tabular}{|c|c|c|c|}
\hline Classification & Variable Name & Variable Type & Expected Sign \\
\hline \multirow{7}{*}{ Structural factors } & Building age & Continuous & Negative \\
\hline & Property category & Discrete & Negative \\
\hline & Plot ratio & Continuous & Negative \\
\hline & Property fee & Continuous & Positive \\
\hline & Total number of houses & Discrete & Negative \\
\hline & Greening rate & Continuous & Positive \\
\hline & Total number of buildings & Discrete & Positive \\
\hline \multirow{3}{*}{ Location factors } & Distance to CBD & Continuous & Negative \\
\hline & Distance to nearest top 3 Hospital & Continuous & Negative \\
\hline & Distance to nearest business circle & Continuous & Negative \\
\hline \multirow{7}{*}{ Neighborhood factors } & Number of bus stops within $500 \mathrm{~m}$ & Discrete & Positive \\
\hline & Number of supermarket within $500 \mathrm{~m}$ & Discrete & Positive \\
\hline & Whether there is a metro station within $1 \mathrm{~km}$ & Discrete & Positive \\
\hline & Whether there is a park within $1 \mathrm{~km}$ & Discrete & Positive \\
\hline & Number of elementary school within $1 \mathrm{~km}$ & Discrete & Positive \\
\hline & Number of junior high school within $1 \mathrm{~km}$ & Discrete & Positive \\
\hline & Whether there is key school within $1 \mathrm{~km}$ & Discrete & Positive \\
\hline \multirow{6}{*}{ Water factors } & Distance to water system & Continuous & Negative \\
\hline & Distance to river & Continuous & Negative \\
\hline & Distance to lake & Continuous & Negative \\
\hline & River surface width & Continuous & Positive \\
\hline & Lake surface area & Continuous & Positive \\
\hline & River water quality & Discrete & Negative \\
\hline
\end{tabular}

\subsection{Data Collection and Processing}

The data about housing price and related information mainly come from the real estate information website Fangtian.com. The website is now one of the world's largest real estate network home platforms, with more than 80 million active users, and its data is authoritative and universal. The dataset is collected by programming $\mathrm{R}$ [28] as the code editing language to crawl the static text in the network homepage. Neighborhood and location data are derived from the Goethe Map, which obtains geocoding and surrounding resource data through the perimeter search and POI search capabilities of the Gaudreau Map API platform.

The geographic information of rivers and lakes comes from the national geographic information resource catalog service system, which is operated and updated by the National Basic Geographic Information Center. ArcGIS [29] was used to measure the average width and the area of a water system, and the distance from the plot to the water system and find the nearest distance.

The data of water quality is derived from the information published by Zhengzhou Water Bureau. Messages of the average water quality level of the object water system were collected and calculated during the one-year period from October 2017 to October 2018.

In order to ensure the reliability of the data, the collected data were preprocessed. Firstly, the samples with less than 10 data, abnormal information and missing individual structural information were deleted. Secondly, based on coding and visualizing the plot, the community data away from the main urban area were also deleted. Finally, after measuring the distance from the plot to the water system by GIS, the dataset with a distance more than $5 \mathrm{~km}$ to the river and $10 \mathrm{~km}$ to the lake were deleted. A total of 678 sample points of the plot were obtained, and the description of the data characteristic is summarized in Table 2. 
Table 2. Description of the data characteristic.

\begin{tabular}{|c|c|c|c|c|}
\hline Classification & Variable Name & Unit & Average & $\begin{array}{l}\text { Standard } \\
\text { Deviation }\end{array}$ \\
\hline \multirow{8}{*}{ Structural factors } & Average price in the community & Yuan $/ \mathrm{m}^{2}$ & 15,911 & 3568.4569 \\
\hline & Building age & Years & 12 & 4.2631 \\
\hline & Property category & $0 / 1$ & 0.99 & 0.0146 \\
\hline & Plot ratio & - & 3.93 & 0.0750 \\
\hline & Property fee & Yuan $/ \mathrm{m}^{2}$ & 1.22 & 0.6071 \\
\hline & Total number of houses & Unit & 1315 & 848.1046 \\
\hline & Greening rate & - & 0.33 & 0.0576 \\
\hline & Total number of buildings & Unit & 14 & 9.5716 \\
\hline \multirow{3}{*}{ Location factors } & Distance to CBD & $\mathrm{km}$ & 10.97 & 3.9394 \\
\hline & Distance to nearest top 3 hospital & $\mathrm{km}$ & 1.72 & 0.7986 \\
\hline & Distance to nearest business circle & $\mathrm{km}$ & 2.57 & 1.1837 \\
\hline \multirow{7}{*}{$\begin{array}{l}\text { Neighborhood } \\
\text { factors }\end{array}$} & Number of bus stops within $500 \mathrm{~m}$ & Unit & 8 & 2.9497 \\
\hline & Number of supermarket within $500 \mathrm{~m}$ & Unit & 25 & 10.2882 \\
\hline & Whether there is a metro station within $1 \mathrm{~km}$ & $0 / 1$ & 0.27 & 0.3928 \\
\hline & Whether there is a park within $1 \mathrm{~km}$ & $0 / 1$ & 0.86 & 0.2452 \\
\hline & Number of elementary school within $1 \mathrm{~km}$ & Unit & 2.71 & 1.3817 \\
\hline & Number of junior high school within $1 \mathrm{~km}$ & Unit & 2.00 & 1.4357 \\
\hline & Whether there is key school within $1 \mathrm{~km}$ & $0 / 1$ & 0.25 & 0.3728 \\
\hline \multirow{6}{*}{ Water factors } & Distance to water system & $\mathrm{km}$ & 1.21 & 0.7646 \\
\hline & Distance to river & $\mathrm{km}$ & 1.21 & 0.7687 \\
\hline & Distance to lake & $\mathrm{km}$ & 4.41 & 1.7499 \\
\hline & River surface width & $\mathrm{m}$ & 28.79 & 8.7005 \\
\hline & Lake surface area & $10,000 \mathrm{~m}^{2}$ & 76.14 & 85.4995 \\
\hline & River water quality & Level & 3.78 & 0.6042 \\
\hline
\end{tabular}

\subsection{Model Specification}

According to the basic principles of spatial econometrics, it is necessary to test the spatial autocorrelation effect before studying the spatial effect and establishing the model. Moran's I index is the main measurement index used to test this effect. Opengeoda software [30] was used to analyze the autocorrelation effect of housing price of 678 sample points, and the analysis results are shown in Figure 2. The Moran's I index is 0.6417 , and the $1 \%$ significance level test indicates that the housing price has a strong spatial autocorrelation effect. Spatial lag model is better than spatial error model in explaining spatial autocorrelation of housing prices [17]. Therefore, this paper adopts a spatial lag model to improve the traditional Hedonic price model and prevent spatial autocorrelation of housing prices. In addition, a geographical weighted regression model focusing on the water system factors was established to explore the spatial heterogeneity of their impact on housing prices.

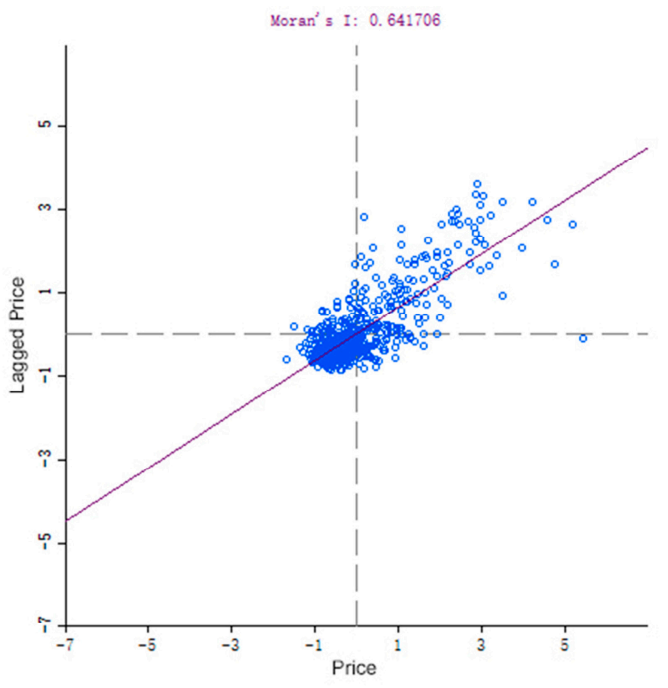

Figure 2. Index. 
In order to explore the spatial effect of the water system on the housing market, seven models are constructed from different aspects in this paper as shown in Table 3.

Table 3. The summary of model setting.

\begin{tabular}{cc}
\hline Name of Model & Setting of Model \\
\hline Model 1 & $\begin{array}{r}\ln P=C+\alpha_{n} \ln S_{n}+\beta_{i} \ln L_{i}+\gamma_{j} N_{j}+\delta \ln D+\varepsilon \\
(n=1,2, \ldots, 7 ; i=1,2,3 ; j=1,2, \ldots, 7)\end{array}$ \\
\hline Model 2 & $\begin{array}{r}\ln P=C+\rho W \ln P+\alpha_{n} \ln S_{n}+\beta_{i} \ln L_{i}+\gamma_{j} N_{j}+\delta \ln D+\varepsilon \\
(n=1,2, \ldots, 7 ; i=1,2,3 ; j=1,2, \ldots, 7)\end{array}$ \\
\hline Model 3 & $\begin{array}{c}\ln P=C+\alpha_{n} \ln S_{n}+\beta_{i} \ln L_{i}+\gamma_{j} N_{j}+\varphi_{m} \ln A_{m}+\varepsilon \\
(n=1,2, \ldots, 7 ; i=1,2,3 ; j=1,2, \ldots, 7 ; m=1,2)\end{array}$ \\
\hline Model 4 & $\begin{array}{c}\ln P=C+\rho W \ln P+\alpha_{n} \ln S_{n}+\beta_{i} \ln L_{i}+\gamma_{j} N_{j}+\varphi_{m} \ln A_{m}+\varepsilon \\
(n=1,2, \ldots, 7 ; i=1,2,3 ; j=1,2, \ldots, 7 ; m=1,2)\end{array}$ \\
\hline Model 5 & $\begin{array}{l}\ln P=C+\alpha_{n} \ln S_{n}+\beta_{i} \ln L_{i}+\gamma_{j} N_{j}+\lambda_{k} E_{k}+\varepsilon \\
(n=1,2, \ldots, 7 ; i=1,2,3 ; j=1,2, \ldots, 7 ; k=1,2,3)\end{array}$ \\
\hline Model 6 & $\begin{array}{c}\ln P=C+\rho W \ln P+\alpha_{n} \ln S_{n}+\beta_{i} \ln L_{i}+\gamma_{j} N_{j}+\lambda_{k} E_{k}+\varepsilon \\
(n=1,2, \ldots, 7 ; i=1,2,3 ; j=1,2, \ldots, 7 ; k=1,2,3)\end{array}$ \\
\hline Model 7 & $W_{i j}=\exp ^{-\left(\frac{d i j}{b}\right)^{2}}$ \\
\hline
\end{tabular}

Note: Where $P$ is the house price, i.e., the average price of the community, $S_{n}$ is the seven structural attributes of the community, $L_{i}$ represents the four location properties of the community, $N_{j}$ is representing the neighborhood attributes of the community, $D$ means the closest distance from the community to the water system, $A_{m}$ represents nearest distance from the plot to the river and lake respectively, $E_{k}$ indicates the characteristic of the water system, including the river surface width, the lake surface area, and the river water quality, $P_{i}$ indicates the housing price of location $i, u_{i}, v_{i}$ indicate the geographic coordinates of observation point $i, Z_{\mathrm{ij}}$ indicates the explanatory variable for housing prices, $d_{\mathrm{ij}}$ represents the distance between observation point $i$ and observation point $j, W_{\mathrm{ij}}$ is the weight matrix, $b$ indicates the bandwidth, and $C, \rho, \alpha_{n}, \beta_{i}, \gamma_{j}, \delta, \varphi_{m}, \lambda_{k}, \phi_{j}$ are the coefficient to be estimated; and $\varepsilon$ is the error term.

Models 1 and 2 explore the influence of the distance from the residential area to the nearest water system (including rivers and lakes) on the housing price from the perspective of accessibility. Model 1 is the traditional Hedonic price model, while Model 2 is the improved spatial lag model considering the housing price space autocorrelation. According to existing research results, the Hedonic price model in logarithmic form has a higher explanatory power than the model in nonlogarithmic form [15]. Therefore, the distance variables in dependent variables were all logarithmically processed, while other variables were represented as linear variables.

In view of the different effects of rivers and lakes on housing prices, Models 3 and 4 explore the impact of community on the nearest river distance and nearest lake distance on housing prices respectively in terms of accessibility. Model 4 is an improved spatial lag model that takes into account the price space autocorrelation.

Considering that accessibility is only one factor affecting housing prices, the characteristics of the water system itself are particularly important. Models 5 and 6 remove the accessibility factors, while add the characteristic factors of the water system into the model. Model 6 is an improved spatial lag model that takes into account the price space autocorrelation.

The traditional Hedonic price model and spatial lag model only consider the average effect of water system on housing prices. In fact, the effect of water system may be spatially heterogeneous. Therefore, the GWR method was introduced in Model 7 to obtain the water system influence coefficient of each location, and then the spatial heterogeneity of water system influence effect was analyzed.

It should be noted that in Model 7, $W_{\mathrm{ij}}$ is also known as the spatial weight function, which is established according to the geographical location coordinates of the observed values. The common spatial weight function includes the following types: distance threshold, distance inverse ratio, gaussian 
function, truncated function, among which Gaussian function is more universal and widely used. The core idea of this method is to select a function of continuous monotone decreasing to represent the relationship between $W_{\mathrm{ij}}$ and $d_{\mathrm{ij}}$. For the selection of spatial weight function, many researchers believe that the selection of kernel function will not have a great impact on the analysis results, while the selection of bandwidth has a great impact on the results [31]. While the bandwidth $b$ directly affects the spatial variation of the GWR model. The determination methods of bandwidth include cross-validation method, AIC criterion, Bayesian information criterion. AIC criterion is widely used in statistics, and was applied to the selection of the best bandwidth in the geographical weighted regression model by Fotheringham. That is, when the AIC value of GWR model is the lowest, the bandwidth is the best choice [32]. In this paper, the Gaussian kernel function is used as spatial weight function and AIC criterion is used as the optimal bandwidth selection criterion.

\section{Research Results}

\subsection{Results Analysis of Traditional Model}

Models 1-6 are estimated by OpenGeoDa software, and the results are presented in Table 4. The results demonstrate that the $\mathrm{F}$ value of the traditional Hedonic price model (i.e., Model 1, Model 3 and Model 5) is close to 0 , indicating that the model has passed the significance test and that all models are valid. The values of adjusted R-square for the three models are: $0.6316,0.6428,0.6284$, which indicate that the model has a strong ability to interpret and can explain more than $60 \%$ of house price changes. The VIF value of all variables is lower than 7.5, indicating that there is no redundancy in the explanatory variable, and the multi-collinear effects of model variables are controllable. Most of the variables in the input model pass the $5 \%$ significance test and only individual explanatory variables are opposite to the expected symbol. In general, the establishment of the model is relatively successful, and most of the water system factors have passed the significance test, indicating that the water system has a significant impact on the housing price in Zhengzhou housing market.

Table 4. Results of parameter estimation of Models 1-6.

\begin{tabular}{lcccccc}
\hline & Model 1 & Model 2 & Model 3 & Model 4 & Model 5 & Model 6 \\
\hline R-square & 0.6414 & 0.6872 & 0.6528 & 0.6906 & 0.6393 & 0.6887 \\
Adjusted R-square & 0.6316 & - & 0.6428 & - & 0.6284 & -0.0000 \\
Prob(F-statistic) & 0.0000 & - & 0.0000 & - & -282.0740 & 324.8570 \\
Log likelihood & 284.0520 & 324.0610 & 294.9640 & 328.5710 & -62.1480 & -605.7150 \\
Akaike info criterion & -530.1000 & -608.1230 & -549.9270 & -615.1430 & -522.140 \\
Schwarz criterion & -444.2400 & -517.7400 & -459.5440 & -520.2400 & -427.2460 & -506.2940 \\
\hline
\end{tabular}

Both Models 1 and 2 are relatively basic model, which explore the influence of a water system on housing price by measuring the distance from the community to a water system. The regression results are shown in Table 5. According to model 1, it is found that the distance from the community to the water system is significant at the level of $1 \%$, and the regression coefficient is -0.0278 , indicating that the distance from the community to the water system increase by $1 \%$, then the housing price of the community will decline by $2.78 \%$.

In Zhengzhou City, the current average price of housing about 15,000 yuan $/ \mathrm{m}^{2}$, which indicates that the price of housing near a water system is approximately 300 yuan $/ \mathrm{m}^{2}$ higher than that far away from the water system. As expected, water system will have an impact on people's daily life, and more and more people pay attention to their own living environment, which indicates that people are willing to pay a certain premium for living around the water system. At the same time, the result also indirectly indicates that more and more housing demand is changing from simple rigid demand to environmental improvement demand. 
Table 5. Regression results of Models 1 and 2.

\begin{tabular}{|c|c|c|c|c|c|}
\hline \multirow[b]{2}{*}{ Variable Name } & \multicolumn{2}{|c|}{ Model 1} & \multicolumn{3}{|c|}{ Model 2} \\
\hline & $\begin{array}{l}\text { Standard } \\
\text { Coefficient }\end{array}$ & $p$-Value & VIF [c] & $\begin{array}{l}\text { Standard } \\
\text { Coefficient }\end{array}$ & $p$-Value \\
\hline Constant & 11.1037 & 0.0000 & - & 6.2393 & 0.0000 \\
\hline Building age & -0.0164 & 0.0000 & 2.8060 & -0.0160 & 0.0000 \\
\hline Property category & -0.2431 & 0.0032 & 1.2820 & -0.3217 & 0.0000 \\
\hline Plot ratio & -0.0622 & 0.0018 & 2.2902 & -0.0495 & 0.0069 \\
\hline Property fee & 0.1003 & 0.0000 & 2.5632 & 0.0843 & 0.0000 \\
\hline Total number of houses & -0.0727 & 0.0000 & 2.8700 & -0.0607 & 0.0000 \\
\hline Greening rate & 0.0493 & 0.0302 & 1.1425 & 0.0576 & 0.0058 \\
\hline Total number of buildings & 0.1068 & 0.0000 & 3.0829 & 0.0913 & 0.0000 \\
\hline Distance to CBD & -0.2714 & 0.0000 & 1.5551 & -0.1575 & 0.0000 \\
\hline Distance to nearest top 3 Hospital & -0.0431 & 0.0001 & 1.4016 & -0.0377 & 0.0001 \\
\hline Distance to nearest business circle & -0.0814 & 0.0000 & 1.4719 & -0.0637 & 0.0000 \\
\hline Number of bus stops within $500 \mathrm{~m}$ & 0.0012 & 0.5534 & 1.3822 & -0.0017 & 0.3688 \\
\hline Number of supermarkets within $500 \mathrm{~m}$ & -0.0026 & 0.0000 & 1.6703 & -0.0010 & 0.0789 \\
\hline Whether there is a metro station within $1 \mathrm{~km}$ & -0.0214 & 0.1603 & 1.1840 & -0.0122 & 0.3836 \\
\hline Whether there is a park within $1 \mathrm{~km}$ & 0.0334 & 0.0758 & 1.1222 & 0.0393 & 0.0229 \\
\hline Number of elementary schools within $1 \mathrm{~km}$ & -0.0020 & 0.6461 & 1.4811 & 0.0026 & 0.5197 \\
\hline Number of junior high school within $1 \mathrm{~km}$ & 0.0264 & 0.0000 & 1.4111 & 0.0216 & 0.0000 \\
\hline Whether there is key school within $1 \mathrm{~km}$ & 0.0522 & 0.0004 & 1.0552 & 0.0422 & 0.0019 \\
\hline Distance to water system & -0.0278 & 0.0000 & 1.1721 & -0.0214 & 0.0002 \\
\hline $\mathrm{W}^{*} \ln \mathrm{P}$ & - & - & - & 0.4761 & 0.0000 \\
\hline
\end{tabular}

The distance from the residential area to the river and lake, which instead of the variable of the distance to the river system, was added to the Models 3 and 4 to explore the heterogeneity of the influence separately. The regression results are shown in Table 6. The adjusted R-square of Model 3 (0.6428) is higher than that of Model 1 (0.6316), indicating that Model 3 has more explanatory power and it is more convincing to consider the influence of rivers and lakes on housing prices separately. According to Model 3 and Model 4, the distance from the community to the river and lake all passed the significance test of $1 \%$, indicating that this factor has an impact on the housing price.

Table 6. Regression results of Models 3 and 4.

\begin{tabular}{|c|c|c|c|c|c|}
\hline \multirow[b]{2}{*}{ Variable Name } & \multicolumn{2}{|c|}{ Model 3} & \multicolumn{3}{|c|}{ Model 4} \\
\hline & $\begin{array}{l}\text { Standard } \\
\text { Coefficient }\end{array}$ & $p$-Value & VIF[c] & $\begin{array}{l}\text { Standard } \\
\text { Coefficient }\end{array}$ & $p$-Value \\
\hline Constant & 11.1488 & 0.0000 & - & 6.5951 & 0.0000 \\
\hline Building age & -0.0166 & 0.0000 & 2.8070 & -0.0161 & 0.0000 \\
\hline Property category & -0.2735 & 0.0008 & 1.2910 & -0.3347 & 0.0000 \\
\hline Plot ratio & -0.0591 & 0.0027 & 2.0990 & -0.0488 & 0.0075 \\
\hline Property fee & 0.0978 & 0.0000 & 2.5676 & 0.0839 & 0.0000 \\
\hline Total number of houses & -0.0705 & 0.0000 & 2.8735 & -0.0601 & 0.0000 \\
\hline Greening rate & 0.0572 & 0.0111 & 1.1514 & 0.0616 & 0.0031 \\
\hline Total number of buildings & 0.1036 & 0.0000 & 3.0925 & 0.0904 & 0.0000 \\
\hline Distance to CBD & -0.2630 & 0.0000 & 1.5786 & -0.1600 & 0.0000 \\
\hline Distance to nearest top 3 hospital & -0.0353 & 0.0011 & 1.4422 & -0.0334 & 0.0008 \\
\hline Distance to nearest business circle & -0.0628 & 0.0000 & 1.6936 & -0.0537 & 0.0000 \\
\hline Number of bus stops within $500 \mathrm{~m}$ & 0.0005 & 0.7872 & 1.3904 & -0.0019 & 0.3144 \\
\hline Number of supermarkets within $500 \mathrm{~m}$ & -0.0020 & 0.0013 & 1.7589 & -0.0008 & 0.1889 \\
\hline Whether there is a metro station within $1 \mathrm{~km}$ & -0.0292 & 0.0537 & 1.1985 & -0.0176 & 0.2097 \\
\hline Whether there is a park within $1 \mathrm{~km}$ & 0.0346 & 0.0617 & 1.1225 & 0.0397 & 0.0210 \\
\hline Number of elementary schools within $1 \mathrm{~km}$ & 0.0026 & 0.5666 & 1.5616 & 0.0051 & 0.2230 \\
\hline Number of junior high schools within $1 \mathrm{~km}$ & 0.0294 & 0.0000 & 1.4565 & 0.0238 & 0.0000 \\
\hline Whether there is key school within $1 \mathrm{~km}$ & 0.0502 & 0.0006 & 1.0561 & 0.0417 & 0.0021 \\
\hline Distance to river & -0.0231 & 0.0002 & 1.2160 & -0.0192 & 0.0010 \\
\hline Distance to lake & -0.0568 & 0.0000 & 1.5949 & -0.0342 & 0.0039 \\
\hline $\mathrm{W}^{*} \ln \mathrm{P}$ & - & - & - & 0.4439 & 0.0000 \\
\hline
\end{tabular}

However, it can also be seen that the impact of lakes (0.0568) on housing prices in residential areas is about twice as great as that of rivers (0.0231) according to the above results, which indicate that people prefer lakes than rivers. On the one hand, the scarcity leads to people's chasing behavior 
because there are fewer lakes than rivers in urban areas. On the other hand, lakes have inherent advantages in terms of the visual field, regional climate influence, and even surrounding environmental facilities due to their aggregation compared with rivers.

Model 5 and Model 6 explore the impact on housing prices from the perspective of the characteristics of the water system without the accessibility variable, and the regression results are shown in Table 7 .

Table 7. Regression results of Models 5 and 6.

\begin{tabular}{|c|c|c|c|c|c|}
\hline \multirow[b]{2}{*}{ Variable Name } & \multicolumn{2}{|c|}{ Model 5} & \multicolumn{3}{|c|}{ Model 6} \\
\hline & $\begin{array}{l}\text { Standard } \\
\text { Coefficient }\end{array}$ & $p$-Value & VIF[c] & $\begin{array}{l}\text { Standard } \\
\text { Coefficient }\end{array}$ & $p$-Value \\
\hline Constant & 11.1992 & 0.0000 & - & 6.1310 & 0.0000 \\
\hline Building age & -0.0171 & 0.0000 & 2.8840 & -0.0169 & 0.0000 \\
\hline Property category & -0.2646 & 0.0016 & 1.3079 & -0.3559 & 0.0000 \\
\hline Plot ratio & -0.0563 & 0.0050 & 2.1059 & -0.0474 & 0.0097 \\
\hline Property fee & 0.0983 & 0.0000 & 2.5671 & 0.0824 & 0.0000 \\
\hline Total number of houses & -0.0735 & 0.0000 & 2.8832 & -0.0593 & 0.0000 \\
\hline Greening rate & 0.0443 & 0.0535 & 1.1510 & 0.0541 & 0.0098 \\
\hline Total number of buildings & 0.1082 & 0.0000 & 3.0879 & 0.0922 & 0.0000 \\
\hline Distance to CBD & -0.2869 & 0.0000 & 1.9000 & -0.1503 & 0.0000 \\
\hline Distance to nearest top 3 hospital & -0.0342 & 0.0020 & 1.4594 & -0.0327 & 0.0012 \\
\hline Distance to nearest business circle & -0.0804 & 0.0000 & 1.5764 & -0.0575 & 0.0000 \\
\hline Number of bus stops within $500 \mathrm{~m}$ & 0.0016 & 0.4211 & 1.3906 & -0.0017 & 0.3613 \\
\hline Number of supermarkets within $500 \mathrm{~m}$ & -0.0023 & 0.0003 & 1.7546 & -0.0010 & 0.0924 \\
\hline Whether there is a metro station within $1 \mathrm{~km}$ & -0.0156 & 0.3117 & 1.1954 & -0.0045 & 0.7465 \\
\hline Whether there is a park within $1 \mathrm{~km}$ & 0.0336 & 0.0763 & 1.1350 & 0.0366 & 0.0350 \\
\hline Number of elementary schools within $1 \mathrm{~km}$ & -0.0052 & 0.2507 & 1.5644 & -0.0013 & 0.7622 \\
\hline Number of junior high schools within $1 \mathrm{~km}$ & 0.0242 & 0.0000 & 1.4238 & 0.0203 & 0.0000 \\
\hline Whether there is key school within $1 \mathrm{~km}$ & 0.0432 & 0.0045 & 1.1037 & 0.0347 & 0.0123 \\
\hline River surface width & 0.0021 & 0.0062 & 1.5138 & 0.0013 & 0.0633 \\
\hline Lake surface area & -0.0003 & 0.6919 & 1.6910 & -0.0001 & 0.1015 \\
\hline River water quality & -0.0244 & 0.0384 & 1.7957 & -0.0357 & 0.0009 \\
\hline $\mathrm{W}^{*} \ln \mathrm{P}$ & $\longrightarrow$ & - & - & 0.5010 & 0.0000 \\
\hline
\end{tabular}

It is noted that the variable of river width passed the $1 \%$ significance test and has a positive impact on the housing price from Model 5 . The price will increase by $0.23 \%$ if the distance from a house to a river increases by $1 \mathrm{~km}$. The variable of river water quality passed the $5 \%$ significance test, and every unit reduction in the river's water quality rating results in a $2.44 \%$ drop in the price of housing in the community. It can be seen that the river width and water quality level all have a greater impact on housing prices, and especially the good water quality is a prerequisite for people to pay a premium [33].

The lake area variable failed to pass the significance test because the analysis in this paper only took into account the physical characteristics and natural factors of the lake, while the external characters assigned by the public, such as the political, economic and cultural factors, were not taken into account. For example, Ruyihu is the smallest lake analyzed in this paper, but the impact of this lake on housing prices is more significant, because this lake is located in the core area of financial center of Zhengzhou city and gathered a large number of high-quality resources around.

\subsection{Result Analysis of Spatial Lag Model}

Models 2, 4 and 6 are spatial econometric models, which all take into account the autocorrelation of housing prices. The spatial matrix in the model can be better interpreted by the second order of the latter formula according to the multiple fitting experiments. According to the results of the Table 2, it can be seen that the R-square of three spatial econometric model (i.e., 0.6872, 0.6906, 0.6887) are higher than the traditional Hedonic price model, the LIK values of the spatial econometric model are greater than the traditional model, and the AIC and SC values are less than the traditional model, which demonstrate that the spatial econometric model has more explanatory power than the traditional model and improves the fit degree of the traditional model. 
The results of the spatial econometric model are basically consistent with the results of the traditional model, and the distance to water system, river, lake and river water quality variables are all significant at the level of $1 \%$. Considering the spatial effect, the river width variable is significant at the $10 \%$ level, while the influence of lake area on housing price is still insignificant. Compared with the regression coefficient of the traditional model, the regression coefficient of variables in the spatial econometric model is reduced to some extent, which indicate that the traditional Hedonic price model does not take into account the spatial autocorrelation effect of housing price and overestimates the influence of water system on housing price in the residential area.

\subsection{Results Analysis of GWR Model}

Combining with Model 7, three geologically weighted regression models were constructed to explore the spatial heterogeneity of the influence of water system on housing price from the three aspects of water system accessibility, river and lake accessibility and water system property. The spatial statistics toolbox of ArcGIS is used to estimate the model. In order to avoid the setting error of local multiple generality of variables, the selected explanatory variables were estimated iteratively, and some of them are selected under the condition of ensuring enough explanatory variables and better explanatory effect. The basic variables include building age, plot ratio, property fee, greening rate, total number of buildings, distance to CBD, distance to the nearest top three hospital, distance to the nearest business circle, number of junior high within $1 \mathrm{~km}$, number of supermarket within $500 \mathrm{~m}$, and Whether there is key school nearby, while the water system variables are still the six variables mentioned above.

The estimated results of the global parameter of the above three models are shown in Table 8, which indicate that the fitting effect of the three models are relatively good, and the spatial heterogeneity effect of the water system can be analyzed through the constructed model.

Table 8. Results of parameter estimation of Model 7.

\begin{tabular}{lccc}
\hline & $\begin{array}{c}\text { Water System } \\
\text { Accessibility }\end{array}$ & $\begin{array}{c}\text { River and Lake } \\
\text { Accessibility }\end{array}$ & $\begin{array}{c}\text { Nature of the Water } \\
\text { System }\end{array}$ \\
\hline R-square & 0.6145 & 0.6174 & 0.5687 \\
Adjusted R-square & 0.6054 & 0.6089 & 0.5601 \\
Akaike info criterion & -486.3656 & -491.5502 & -415.6654 \\
\hline
\end{tabular}

In order to make the results more intuitive, the regression results for each model are presented in the form of maps. Figure 3 is the p-value and the local regression coefficient diagram of the distance variables to water system. From the p-value diagram in Figure $3 \mathrm{a}$, it can be found that the $p$-value of this variable at all observation points has passed the significance test of $1 \%$, indicating that it is valid within all observation ranges and further proving that the water system has a significant impact on the housing price. As can be seen from Figure $3 b$, the regression coefficient of the distance variable to the water system is all negative in the whole research area. In addition, the coefficient distribution gradually creases from northwest to southeast, reaching a peak value of -0.0357 in the southeast.

The above analysis results show that there are differences in the spatial distribution of the effect of the water system on the housing price in Zhengzhou. The influence in the east is greater than that in the central and western regions. The reasons for this can be explained from two aspects. Firstly, according to Figure 4, it can be observed that the distance between the western urban area and the water system is farther than the other areas. The fact of the matter is that the water resources of the eastern urban areas are more abundant than in the western urban areas, and the landscape of water system is also better, so the impact of the water system on the eastern urban area is more significant. Secondly, the housing of the main central urban area is mostly built in the last century and the building age of central urban area is earlier than the surrounding area. The residents of this area are mostly rigid demand users and they pay little attention to the surrounding natural environment, so the impact 
of the water system is not significant compared to the eastern district. At the same time, the poor river environment and less green space in this area are also found to be reasons.

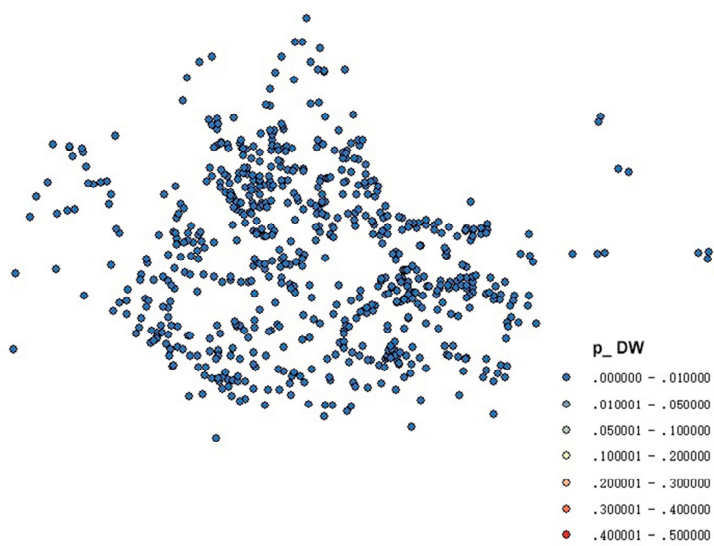

(a)

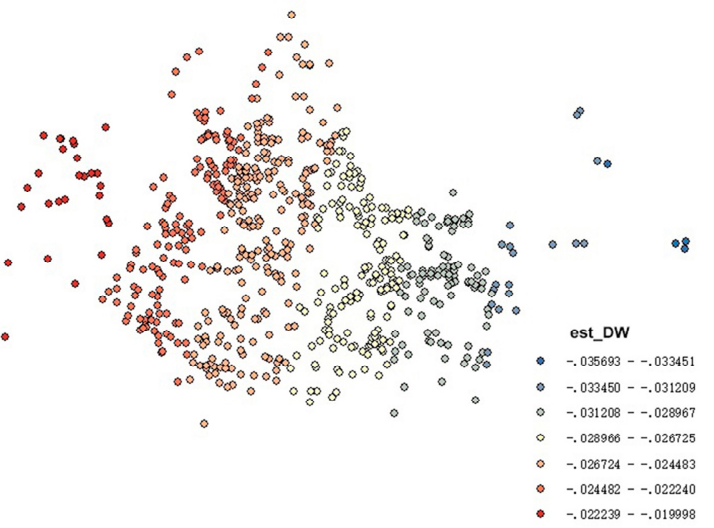

(b)

Figure 3. P-value (a) and regression coefficient distribution (b) of distance to water system.

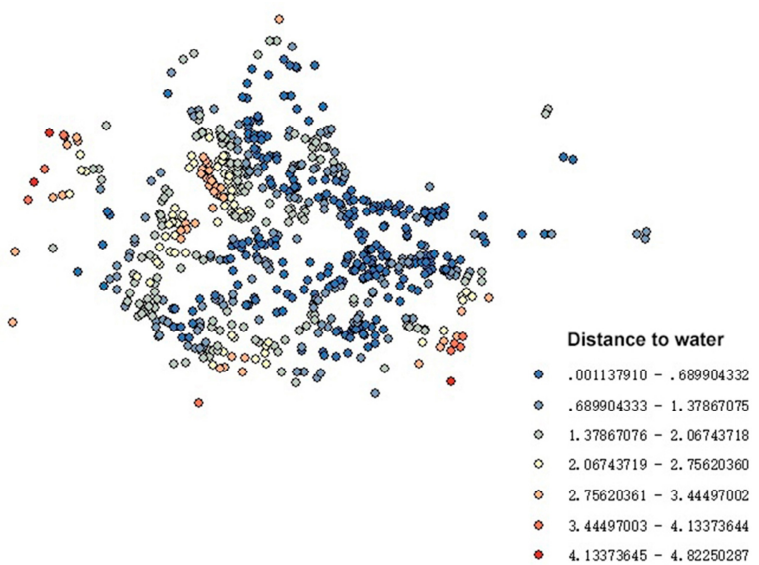

Figure 4. The distribution of distance to water system.

P-value test chart of the river and lake accessibility is shown in Figure $5 a, b$, and all observation points pass the $1 \%$ significance test, indicating that the accessibility of rivers and lakes has a significant impact on housing prices. Figure $6 \mathrm{a}, \mathrm{b}$ and show the corresponding coefficient distribution diagram, which is roughly the same as the accessibility of the water system. The coefficients in the study area are all negative and distributed in a crease pattern of reaching their peaks in the southeast of the city, respectively in -0.0265 and -0.0580 . It can be seen that the influence effect of lakes was still greater than that of rivers, and the influence of accessibility of rivers and lakes on the eastern urban area was greater than that of the central and western urban area, which show that the spatial distribution of the influence effect of rivers and lakes on housing prices is not uniform, and the influence effect of lakes is greater than that of rivers. 


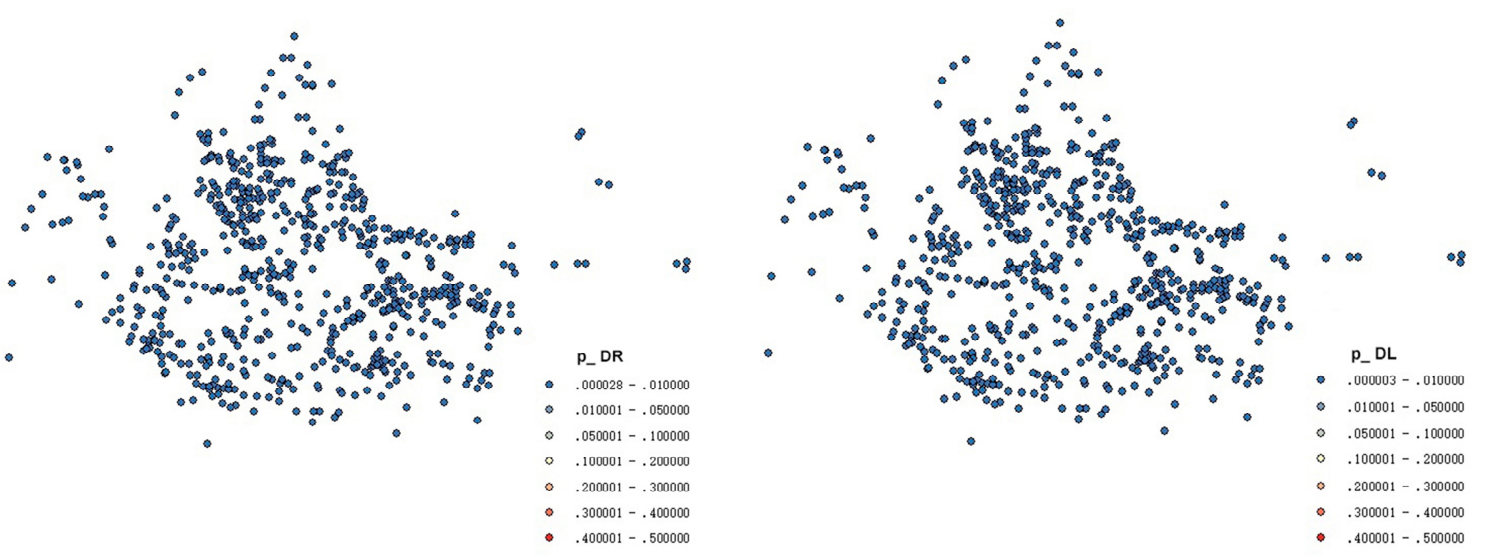

(a)

(b)

Figure 5. P-value distribution of distance to river (a) and lake (b).

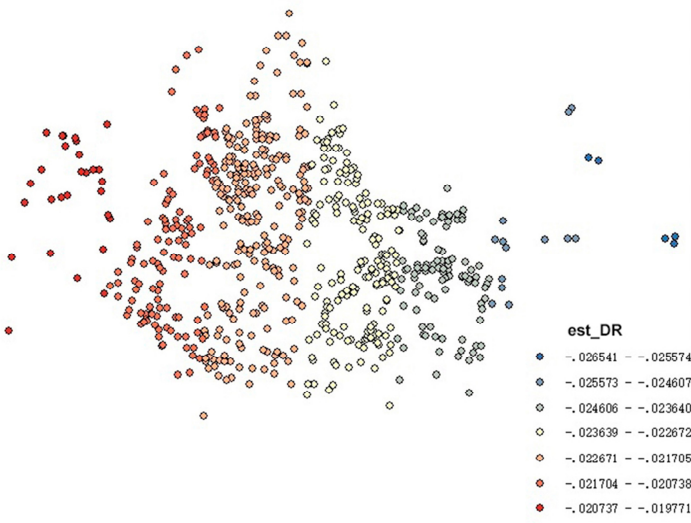

(a)

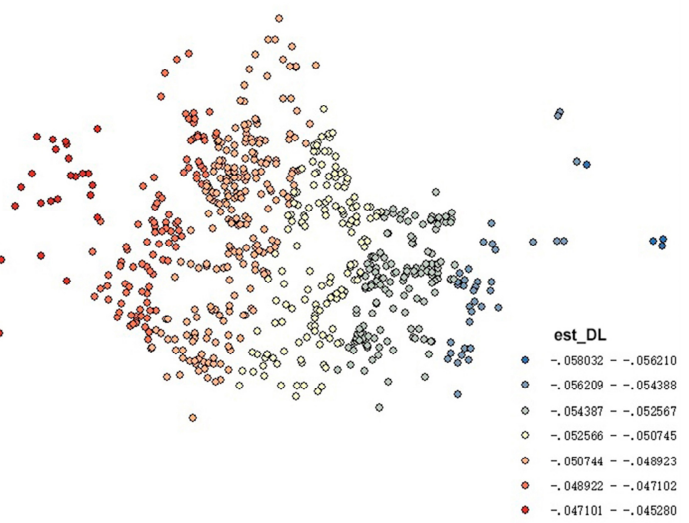

(b)

Figure 6. Regression coefficient distribution of distance to river (a) and lake (b).

The regression results of GWR model for river system properties (i.e., river width, lake area and river water quality) are likewise measured. Figure $7 \mathrm{a}-\mathrm{c}$ are the $\mathrm{p}$-values of the three variables, and Figure $8 \mathrm{a}-\mathrm{c}$ are the corresponding regression coefficients of the three variables. From the $p$-value diagram of the width of the river (in Figure 7a), only a few observation points in the northwest are unable to pass the significance test of $5 \%$, while observation points in the rest of the region all pass the test. It can be seen from the distribution diagram that all the coefficients (in Figure 8a) are positive and the distribution is still decreasing from southeast to northwest, which show that the influence of river width factor on housing price exists in most areas, and the influence of river width factor on housing price in the eastern area is greater because most rivers in the eastern area are wider than those in the central and western areas. 


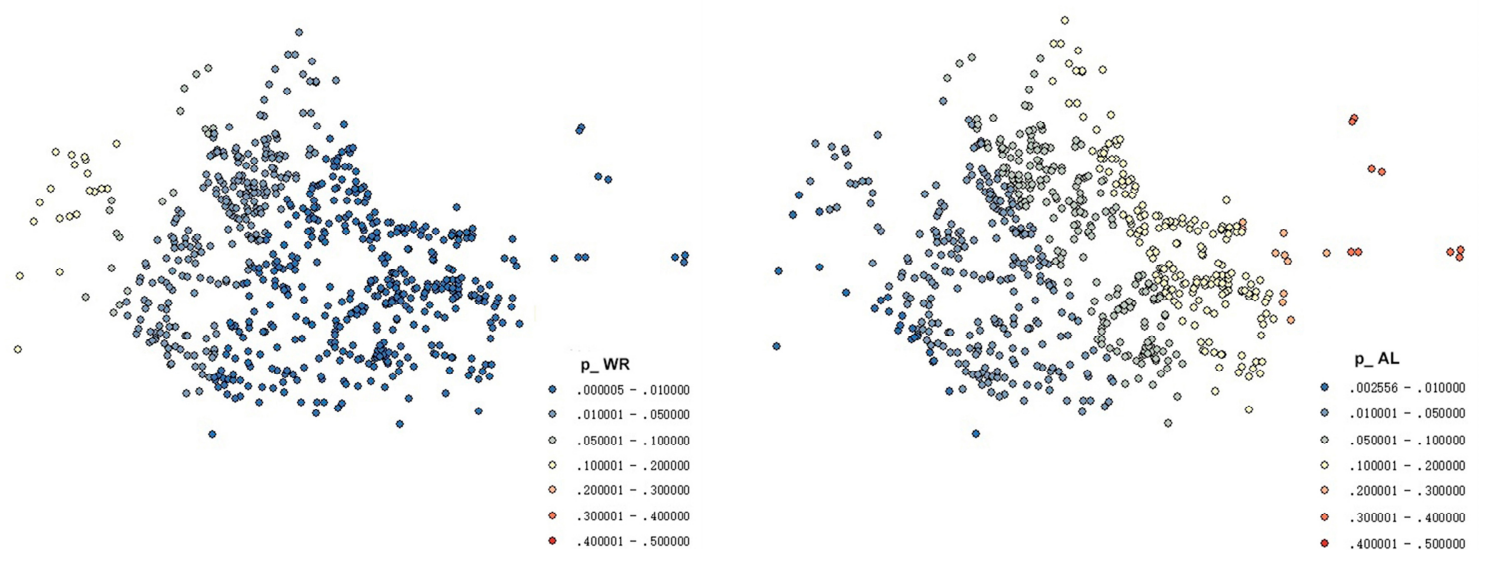

(a)

(b)

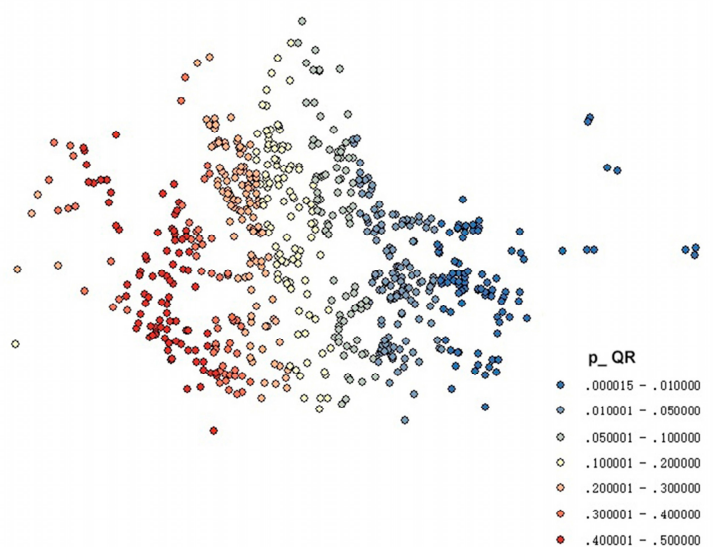

(c)

Figure 7. P-value distribution of river width (a), lake area (b) and river water quality (c).

From the $p$-value diagram of the lake area in Figure $7 \mathrm{~b}$, only observation points in the western urban area pass the significance test of $5 \%$, indicating that the variable of lake area only has a significant impact in this region. According to the coefficient distribution map (in Figure 8b), the effect of lake area on housing price is all positive and decreases gradually from southwest to northeast, and the main influence areas are located close to Xiliuhu. The analysis results of this variable show that the increase of lake area will drive up the housing price in the western part of the city, but not significantly in the eastern part. The reason may be that social, cultural and economic attributes attaching to a lake are often overlooked. 


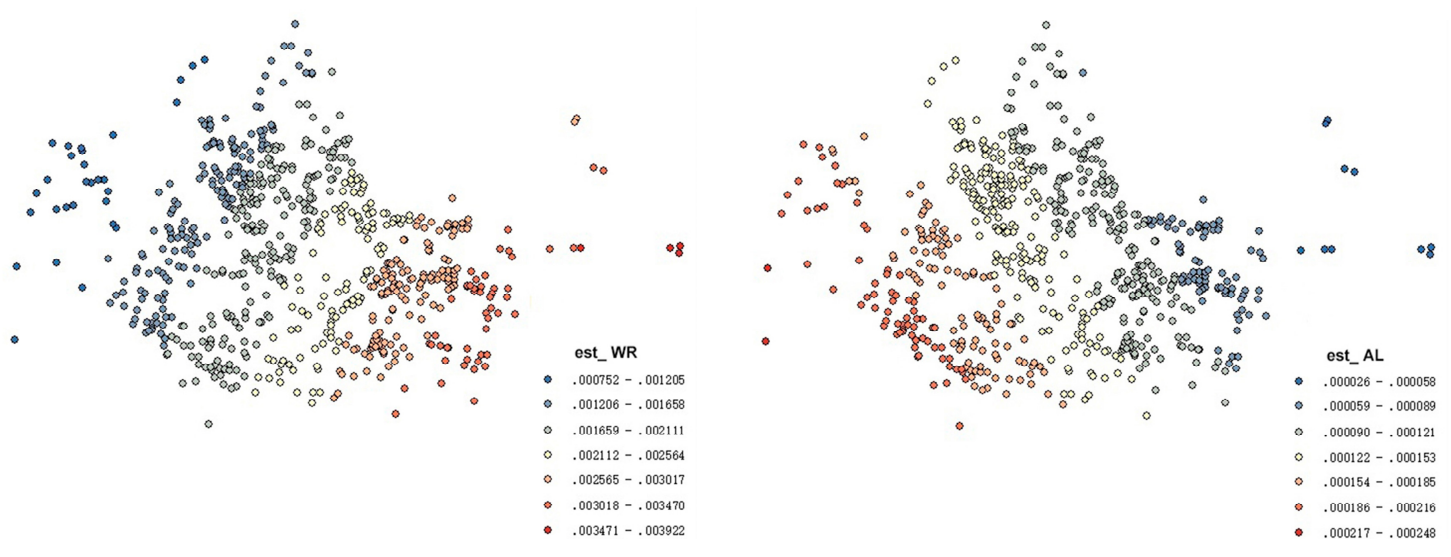

(a)

(b)

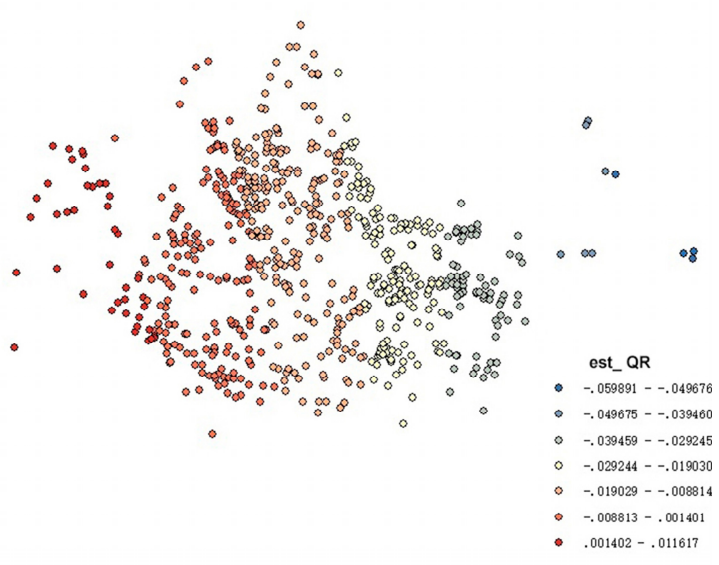

(c)

Figure 8. Regression coefficient distribution of river width (a), lake area (b) and river water quality (c).

It can be observed from the p-value distribution map of river water quality (in Figure $7 \mathrm{c}$ ) that the areas that pass the 5\% significance test are distributed in the eastern region bounded, namely Zhengdong new district. In addition, water quality does not get a significant impact on housing prices elsewhere. According to the regression coefficient distribution diagram as shown in Figure 8c, the regional regression coefficient that has passed the significance test is negative, and the influence effect increases gradually from southwest to northeast. The analysis results of water quality variables show that the river water quality is good in the Zhengdong new district, which has a significant impact on the housing prices in the area.

\subsection{Results Analysis of Exploratory Research}

Some exploratory studies have explored the heterogeneity of spatial effects of different river systems by taking Jinshuihe, Dongfengqu and Ruyihu as research objects. Meanwhile, the communities within $5 \mathrm{~km}$ of the surrounding water system were chosen as observation points, and accessibility was selected as the key explanatory variable. The results in Figure 9a-c show that most observation points around the three water systems pass the significance test of $5 \%$. From the coefficient distribution map of Figure $10 \mathrm{a}-\mathrm{c}$ it can be seen that Jinshuihe has a negative effect on the surrounding housing prices, which may be attributed to the noise and unsafe environment caused by relatively concentrated crowds $[9,34]$. The effect of the Dongfengqu on the surrounding communities gradually increases from 
the northwest to the southeast, while the effect of Ruyihu presents directional heterogeneity, which may be caused by the interactive influence of the eastern high-speed railway business district.

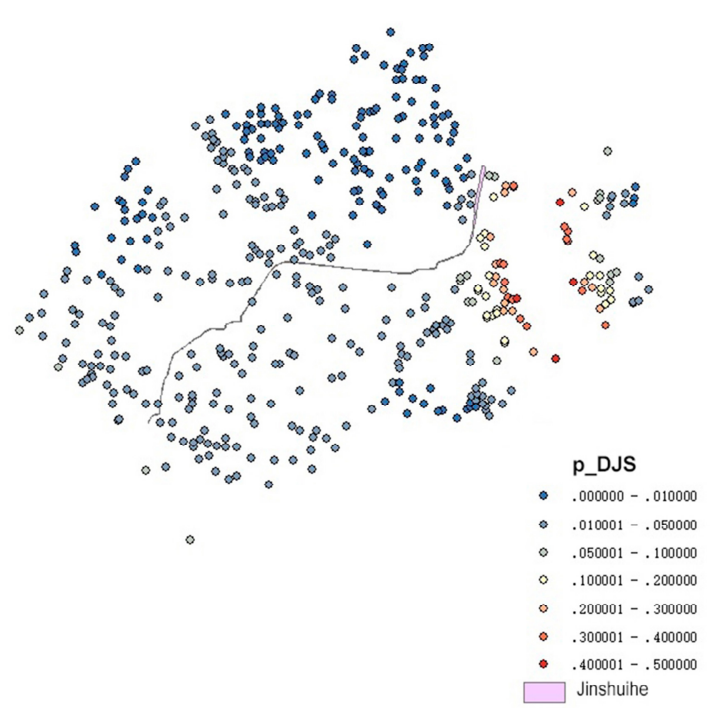

(a)

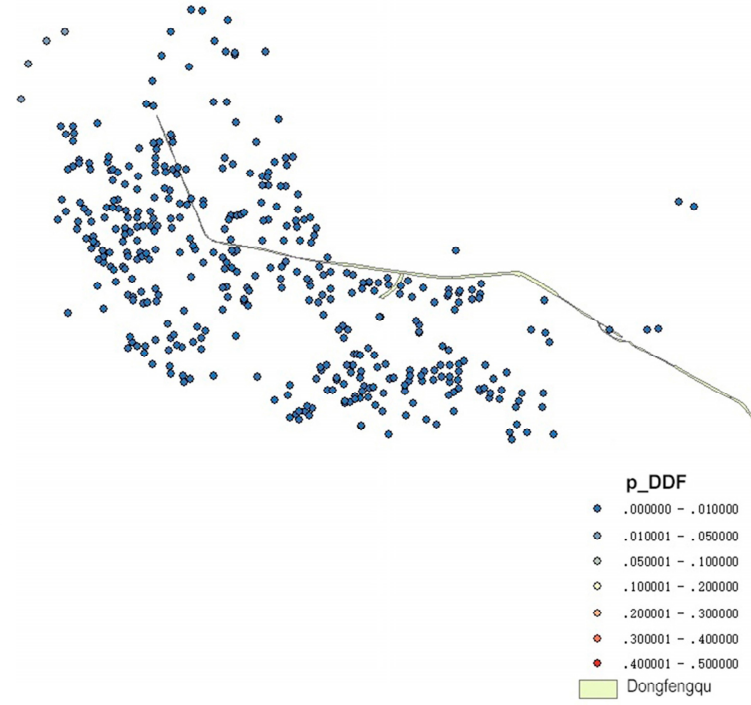

(b)

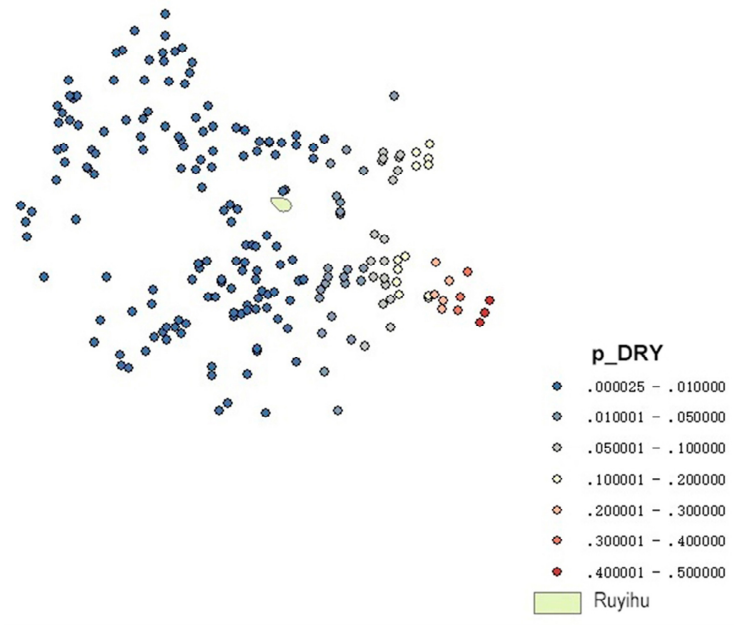

(c)

Figure 9. P-value distribution of distance to Jinshuihe (a), Dongfengqu (b) and Ruyihu (c). 


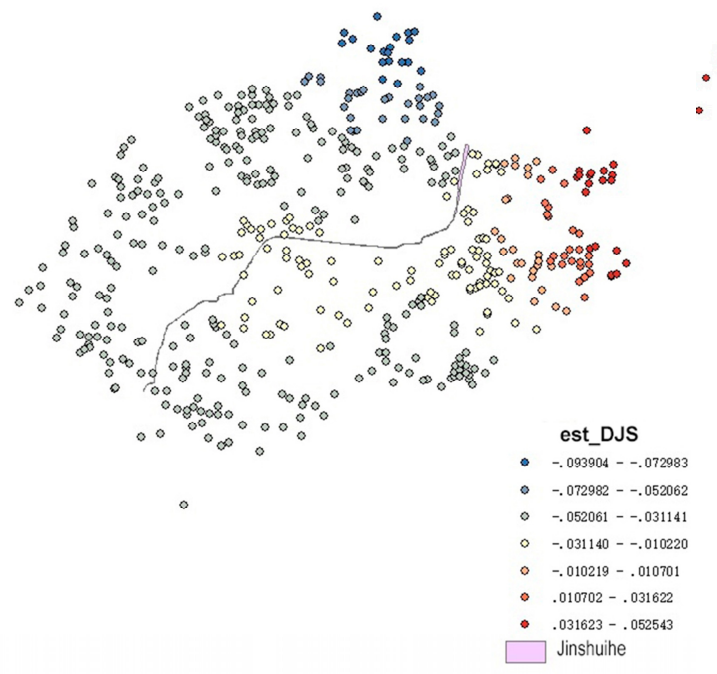

(a)

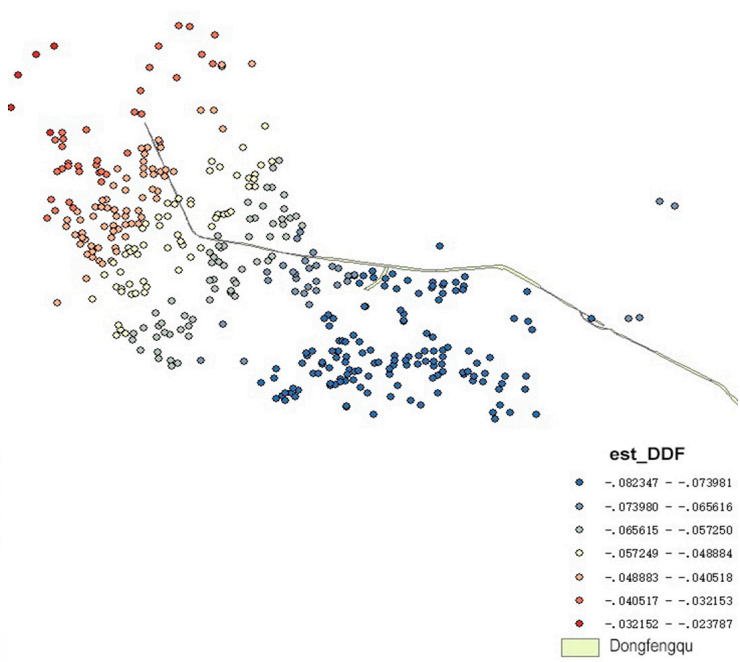

(b)

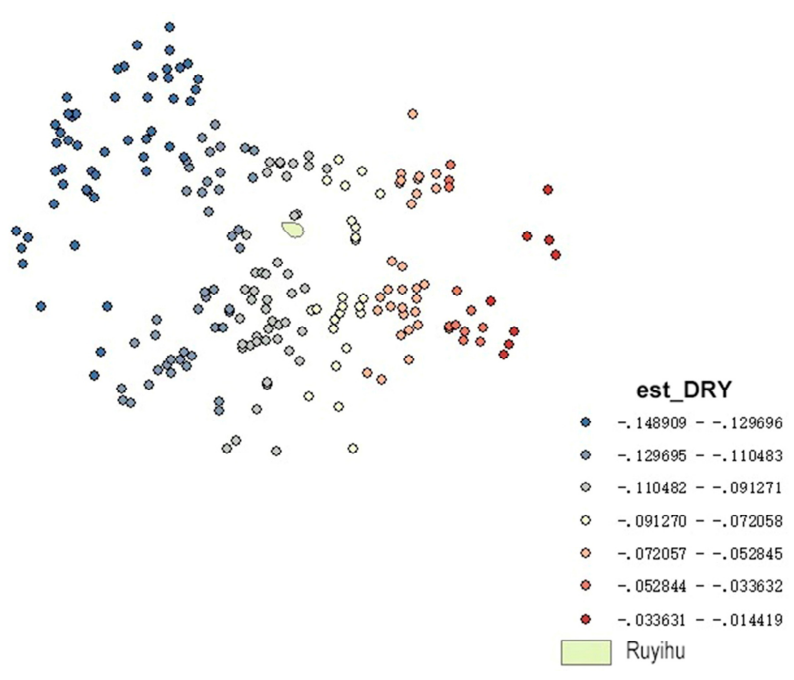

(c)

Figure 10. Regression coefficient distribution of distance to Jinshuihe (a), Dongfengqu (b) and Ruyihu (c).

\section{Discussions and Conclusions}

The effect of a water system on housing price is explored by establishing the traditional Hedonic price model, spatial lag model and GWR model based on collecting the listing transaction data of 678 housing districts in the main urban area of Zhengzhou in this paper. The result of the spatial lag model is similar to the traditional Hedonic price model, while the regression coefficient is reduced, which proves that there is an autocorrelation of housing prices in Zhengzhou. The result also shows that the spatial lag model has a better explanatory power than the traditional Hedonic price model, which overestimates the effect of some variables on housing prices.

The overall perspective suggests that the accessibility from the community to the water system has an impact on the housing price, and the price of the community nearer to the water system is higher. In terms of the heterogeneity influence of water system, there are differences between rivers and lakes in the influence of housing prices. The influence effect of lakes is larger than that of rivers, which may be due to the scarcity of lakes and the aggregation of water bodies. The width and the water quality of the river have a significant impact on the housing price, which demonstrate that the 
wider water area and better water quality in favor of the increase of housing price. While the influence of the lake area was not significant, which may be attributed to the ignorance of the economic, cultural and social attributes of the lake in this paper.

Exploratory studies on housing price around some water systems show that the influence effect of water systems on surrounding communities has directional heterogeneity, which is mainly due to the negative environmental effects of noise, dense population and other factors. The results suggest that the influence effect of the water system may be weakened by the poor environment surrounding.

The results of this paper are of great practical significance to government urban planning, environmental governance and housing market management. As residents pay more and more attention to the living environment around them, especially the water system environment, the government should focus on the water landscape to meet the living needs of residents. First of all, water quality is a necessary prerequisite for a water system to serve urban life, so water quality should be guaranteed. Secondly, the physical properties of the water system should be enhanced by widening and extending the river channels, thus increasing the area of green space around the rivers and lakes. Thirdly, for regions lacking a water system, the number of water systems should be increased through creating surface water or river diversion to meet the living and entertainment needs of the surrounding residents. Considering that the higher influence effect of lakes is higher than that of rivers, man-made lakes should be preferred in the process of water system construction. Fourthly, based on the premise of the inherent natural attributes, more social attributes should be given to the water system, which will make it more influential. For example, the water system can link with science and technology, administration and education, which can better drive regional development. Last but not least, the practice of exaggerating publicity, taking the water system as a marketing gimmick, and then significantly raising housing prices by real estate developers should be prevented and limited in order to promote the sustainable development of the housing market.

As information and communication technologies (ICTs) have become a key tool for cities to enhance innovation and to improve the management of urban services [35-37], it would be interesting as future research avenues to introduce how the advent of smart cities can be used to couple with the management of water systems to promote the surrounding living environment. For example, by collecting social media check-in data related to a certain water system, the feelings of residents about the water, and what needs to be improved to enhance the resident experience and services can be analyzed.

Author Contributions: Conceptualization, J.L.; data curation, Y.H.; supervision, C.L. All authors have read and agreed to the published version of the manuscript.

Funding: This work was supported by the Humanities and Social Science research of Henan Provincial Education Department (Approval No. 2017-ZZJH-527 and 2018-ZZJH-561). The authors also appreciate the gracious support from China Scholarship Council.

Conflicts of Interest: The authors declare no conflicts of interest.

\section{References}

1. Goffette-Nagot, F.; Reginster, I.; Thomas, I. Spatial Analysis of Residential Land Prices in Belgium: Accessibility, Linguistic Border, and Environmental Amenities. Reg. Stud. 2011, 45, 1253-1268. [CrossRef]

2. Maleki, M.Z.; Zain, M.F.M. Factors That Influence Distance to Facilities in a Sustainable Efficient Residential Site Design. Sustain. Cities Soc. 2011, 1, 236-243. [CrossRef]

3. Liu, Z.; Robinson, G.M. Residential Development in the Peri-Urban Fringe: The Example of Adelaide, South Australia. Land Use Policy 2016, 57, 179-192. [CrossRef]

4. Bonetti, F.; Corsi, S.; Orsi, L.; De Noni, I. Canals vs. Streams: To What Extent Do Water Quality and Proximity Affect Real Estate Values? A Hedonic Approach Analysis. Water 2016, 8, 577. [CrossRef]

5. Loomis, J.; Feldman, M. Estimating the Benefits of Maintaining Adequate Lake Levels to Homeowners Using the Hedonic Property Method: Economic benefits of lake levels. Water Resour. Res. 2003, 39, 1-2. [CrossRef] 
6. Wen, H.; Bu, X.; Qin, Z. Spatial Effect of Lake Landscape on Housing Price: A Case Study of the West Lake in Hangzhou, China. Habitat Int. 2014, 44, 31-40. [CrossRef]

7. Sander, H.A.; Polasky, S. The Value of Views and Open Space: Estimates from a Hedonic Pricing Model for Ramsey County, Minnesota, USA. Land Use Policy 2009, 26, 837-845. [CrossRef]

8. Jiao, L.; Liu, Y. Geographic Field Model Based Hedonic Valuation of Urban Open Spaces in Wuhan, China. Landsc. Urban Plan. 2010, 98, 47-55. [CrossRef]

9. Jim, C.Y.; Chen, W.Y. Impacts of Urban Environmental Elements on Residential Housing Prices in Guangzhou (China). Landsc. Urban Plan. 2006, 78, 422-434. [CrossRef]

10. Tapsuwan, S.; Ingram, G.; Burton, M.; Brennan, D. Capitalized Amenity Value of Urban Wetlands: A Hedonic Property Price Approach to Urban Wetlands in Perth, Western Australia. Aust. J. Agric. Resour. Econ. 2009, 53, 527-545. [CrossRef]

11. Hamilton, S.E.; Morgan, A. Integrating Lidar, GIS and Hedonic Price Modeling to Measure Amenity Values in Urban Beach Residential Property Markets. Comput. Environ. Urban Syst. 2010, 34, 133-141. [CrossRef]

12. Jim, C.Y.; Chen, W.Y. External Effects of Neighbourhood Parks and Landscape Elements on High-Rise Residential Value. Land Use Policy 2010, 27, 662-670. [CrossRef]

13. Luttik, J. The Value of Trees, Water and Open Space as Reflected by House Prices in the Netherlands. Landsc. Urban Plan. 2000, 7, 161-167. [CrossRef]

14. Kashian, R.; Eiswerth, M.E.; Skidmore, M. Lake Rehabilitation and the Value of Shoreline Real Estate: Evidence from Delavan, Wisconsin. Rev. Reg. Stud. 2006, 36, 221-238.

15. Ara, S.; Irwin, E.; Haab, T. Measuring the Effects of Lake Erie Water Quality in Spatial Hedonic Price Models. In Proceedings of the 3rd World Congress on Environmental and Resource Economics, Kyoto, Japan, 3-7 July 2006.

16. Liao, F.; Wilhelm, F.; Solomon, M. The Effects of Ambient Water Quality and Eurasian Watermilfoil on Lakefront Property Values in the Coeur d'Alene Area of Northern Idaho, USA. Sustainability 2016, 8, 44. [CrossRef]

17. Wen, H.; Xiao, Y.; Zhang, L. Spatial Effect of River Landscape on Housing Price: An Empirical Study on the Grand Canal in Hangzhou, China. Habitat Int. 2017, 63, 34-44. [CrossRef]

18. Belanger, P.; Bourdeau-Brien, M. The Impact of Flood Risk on the Price of Residential Properties: The Case of England. Hous. Stud. 2018, 33, 876-901. [CrossRef]

19. Daniel, V.E.; Florax, R.J.G.M.; Rietveld, P. Floods and Residential Property Values: A Hedonic Price Analysis for the Netherlands. Built Environ. 2009, 35, 563-576. [CrossRef]

20. Hirsch, J.; Hahn, J. How Flood Risk Impacts Residential Rents and Property Prices: Empirical Analysis of a German Property Market. J. Prop. Investig. Financ. 2018, 36, 50-67. [CrossRef]

21. Jung, E.; Yoon, H. Is Flood Risk Capitalized into Real Estate Market Value? A Mahalanobis-Metric Matching Approach to the Housing Market in Gyeonggi, South Korea. Sustainability 2018, 10, 4008. [CrossRef]

22. Atreya, A.; Czajkowski, J. Graduated Flood Risks and Property Prices in Galveston County. Real Estate Econ. 2019, 47, 807-844. [CrossRef]

23. Wen, H.; Jin, Y.; Zhang, L. Spatial Heterogeneity in Implicit Housing Prices: Evidence from Hangzhou, China. Int. J. Strateg. Prop. Manag. 2017, 21, 15-28. [CrossRef]

24. Yu, H.; Huang, Y. Regional Heterogeneity and the Trans-Regional Interaction of Housing Prices and Inflation: Evidence from China's 35 Major Cities. Urban Stud. 2016, 53, 3472-3492. [CrossRef]

25. Nilsson, P. Natural Amenities in Urban Space-A Geographically Weighted Regression Approach. Landsc. Urban Plan. 2014, 121, 45-54. [CrossRef]

26. Cohen, J.P.; Danko, J.J.; Yang, K. Proximity to a Water Supply Reservoir and Dams: Is There Spatial Heterogeneity in the Effects on Housing Prices? J. Hous. Econ. 2019, 43, 14-22. [CrossRef]

27. Wen, H.; Xiao, Y.; Hui, E.C.M.; Zhang, L. Education Quality, Accessibility, and Housing Price: Does Spatial Heterogeneity Exist in Education Capitalization? Habitat Int. 2018, 78, 68-82. [CrossRef]

28. R-Project.org. Documentation for Package 'Stats' Version 3.6.0. 2019. Available online: https://mirrors.tuna. tsinghua.edu.cn/CRAN/ (accessed on 16 May 2019).

29. GeoDa 1.14. Documentation for Installation Package Version 1.14. 2019. Available online: http://geodacenter. github.io/download_windows.html (accessed on 21 July 2019).

30. ArcGIS Online. Documentation for Installation Package Version Online. 2019. Available online: https: //www.esri.com/en-us/arcgis/products/mapping (accessed on 23 July 2019). 
31. McMillen, D.P.; Redfearn, C.L. Estimation and hypothesis testing for nonparametric hedonic house price functions. J. Reg. Sci. 2010, 50, 712-733. [CrossRef]

32. Brunsdon, C.; Fotheringham, A.S.; Charlton, M. Geographically Weighted Summary Statistics—a Framework for Localised Exploratory Data Analysis. Comput. Environ. Urban Syst. 2002, 26, 501-524. [CrossRef]

33. Zhu, J.; Chen, B.; Lu, P.; Liu, J.; Tang, G. Impact of Urban Water System Treatment on the Surrounding Residential Land Price. Arab. J. Geosci. 2018, 11, 1-11. [CrossRef]

34. Anderson, S.T.; West, S.E. Open Space, Residential Property Values, and Spatial Context. Reg. Sci. Urban Econ. 2006, 36, 773-789. [CrossRef]

35. Harrison, C.; Eckman, B.; Hamilton, R.; Hartswick, P.; Kalagnanam, J.; Paraszczak, J.; Williams, P. Foundations for Smarter Cities. IBM J. Res. Dev. 2010, 54, 1-16. [CrossRef]

36. Muvuna, J.; Boutaleb, T.; Baker, K.J.; Mickovski, S.B. A Methodology to Model Integrated Smart City System from the Information Perspective. Smart Cities 2019, 2, 496-511. [CrossRef]

37. Malandrino, O.; Sica, D.; Supino, S. The Role of Public Administration in Sustainable Urban Development: Evidence from Italy. Smart Cities 2019, 2, 82-95. [CrossRef]

(C) 2020 by the authors. Licensee MDPI, Basel, Switzerland. This article is an open access article distributed under the terms and conditions of the Creative Commons Attribution (CC BY) license (http://creativecommons.org/licenses/by/4.0/). 